\title{
Inbreeding depression for seed germination and seedling vigor in strawberry (Fragaria $\times$ ananassa Duch.)
}

\author{
Elżbieta Kaczmarska*, Jacek Gawroński, Magdalena Dyduch-Siemińska, \\ Piotr Szypiło, Bożena Szafrańska
}

Department of Genetics and Horticultural Plant Breeding University of Life Sciences in Lublin Akademicka 15, 20-950 Lublin, Poland

\begin{abstract}
Experiments leading to the procurement of subsequent inbred generations were conducted in the years 20062013. Seeds obtained from open pollination and after self-pollination of four strawberry cultivars (Teresa, Senga Sengana, Kent and Chandler) and clone 1387 were used. These genotypes were evaluated for their tolerance to strong inbreeding under in vitro culture conditions. The aims of this study were to estimate the inbreeding depression of each of the progenies. During the investigation, the germination percentage as well as seedling viability were evaluated. The highest seed germination was shown for populations derived from 'Teresa' $\times$ open pollination (82\%) and 'Kent' (7) $\mathrm{S}_{4}(78 \%)$. Seeds derived from self-pollination resulted in the lowest germination - an average of $16.8 \%$. Generally, seed germination was significantly lower for the five $S_{1}$ offspring, whose depression was 0.62 , in comparison with the $\mathrm{S}_{4}$ seedlings, whose depression was 0.31 . Inbred offspring showed a depression in relation to the average weight of a single seedling of 0.08 in the case of $S_{1}$ progeny, whereas in the case of $\mathrm{S}_{4}$ progeny it was 0.23 . The highest germination energy was shown by 'Kent' (7) $\mathrm{S}_{4}$ seeds (74\%) and hybrids of 'Teresa' derived from open pollination (75\%); whereas seeds obtained at the same time from self-pollination germinated $10.8 \%$ on average.
\end{abstract}

Key words: breeding; inbreeding coefficient; offspring; pollination; self-pollination

\section{Abbreviations:}

$\delta$ - inbreeding depression coefficients, ws - inbred trait value, wo - outbred trait value, OP - open pollination,

\section{INTRODUCTION}

Since the strawberry (Fragaria $\times$ ananassa Duch. $2 \mathrm{n}=8 \mathrm{x}=56$ ) is a vegetatively propagated crop, and thus highly heterozygous in nature, theoretically inbreeding should reveal undesirable combinations of genes which, once eliminated, should leave plants with a high concentration of desirable characteristics. The remaining inbred lines should then be valuable as parents both in crosses between each other and with cultivars, thus producing progenies with a high proportion of elite selections. The value of inbreeding in strawberries has never been fully resolved (Melville et al.1980, Niemirowicz-Szczytt 1989, Rho et al. 2008, Baturin and Ambros 2010, Rho et al. 2012).

Inbreeding depression is widely observed in animals and plants that reproduce by random mating 
(allogamy) when populations are submitted to any natural or artificial inbreeding. This phenomenon is related to an increase in homozygosity at loci with some degree of dominance (Charlesworth and Charlesworth 1987). The effects of inbreeding depression are probably due to a large number of genes with small effects and varying degrees of dominance, or to key genes that affect several other genes of smaller effect (Chaves et al. 2010). However, inbreeding depression is a quantitative character, whose expression is environmentally dependent, and alternative methods to measure it, involving a minimum of artificial disturbance, need investigation. In vitro cultures are a perfect method for the observation of seed germination and also of the influence of inbreeding on this process. These observations can be carried out in the small space of an in vitro lab and can be screened in strictly controlled conditions.

The basis for assessing the germination is the assumption that the seeds that developed normally shoot at the time and conditions specific to the species and will be capable of further development in field conditions. Germination capacity is the percentage of seeds germinated normally in the conditions and time allowed for the completion of the evaluation (Duczmal 1993). The evaluation of germinating seeds should be carried out in a period of their development when we can determine whether seedlings have normally developed vital organs. Normal seedlings should have: a welldeveloped root system, a well-developed over - or under - cotyledonous part, one cotyledon in monocotyledon seedlings and two cotyledons in dicotyledonous seedlings (Duczmal and Tucholska 2000).

The aim of the undertaken studies was to estimate the effect of inbreeding on seed germination in the tested populations of strawberry. In this study we evaluated the percentage of germinating seeds and seedling viability of populations $\mathrm{S}_{1}$ and $\mathrm{S}_{4}$ derived from four strawberry cultivars and clone 1387.

\section{MATERIAL AND METHODS}

Ten strawberry cultivars including Kent, Selva, Elkat, Elsanta, Paula, Ostara, Teresa, Senga Sengana, Chandler and the breeding clone 1387 were examined and self-pollinated, but only five of them (Teresa, Senga Sengana, Kent, Chandler and clone 1387) developed successive inbreeding generations $\left(\mathrm{S}_{2}-\mathrm{S}_{4}\right)$.

Seeds from open pollination were collected from these plants grown in the field strawberry germplasm collection. In the obtained seeds, high genetic diversity was expected as a result of random chromosome segregation and crossingover during megasporogenesis in the mother plants, and of random pollination by the pollen from over 80 cultivars and clones of different origin growing in the proximity of the maternal plants.

To obtain the fourth generation $\left(\mathrm{S}_{4}\right)$, the first self-pollination was performed in May 2006. Before flowering time, inflorescences were covered with small bags made of cloth and left undisturbed for spontaneous selfing. 150 seedlings $\left(S_{1}\right)$ derived from each of the cultivars were used in field trials on September 10, 2007. In May 2008, the second self-pollination was performed. Twenty seedlings randomly chosen from the first generation were self-pollinated to generate the second generation $\left(\mathrm{S}_{2}\right)$. In 2010, 20 seedlings were retained from these populations and used as parents to obtain the third generation. Seeds of the population $\mathrm{S}_{4}$ and $S_{1}$ were obtained in 2012 (according to the procedure described above). Progeny $\mathrm{S}_{4}-$ marked with corresponding numbers - was derived from the same $\mathrm{S}_{3}$ parental plants. The obtained seeds were divided into two parts, and the experiment was repeated twice in 2013.

\section{In vitro germination procedure}

Seeds were surface sterilized in sodium hypochlorite for 2 hours, rinsed three times in sterile distilled water (for 5, 10 and $15 \mathrm{~min}$.) and placed on a medium composed of macro- and microelements according to Murashige and Skoog (1962). The medium was enriched in $100 \mathrm{mg} \mathrm{dm}^{-3}$ of m-inositol, $20 \mathrm{~g} \mathrm{dm}^{-3}$ of sucrose, $7 \mathrm{~g} \mathrm{dm}^{-3}$ of agar, $\mathrm{pH}$ 5.65 adjusted with $0.1 \mathrm{~N} \mathrm{NaOH}$ and $0.1 \mathrm{~N} \mathrm{HCl}$ prior to autoclaving, then was sterilized for 20 minutes at $121^{\circ} \mathrm{C}$ in Petri dishes $(10 \mathrm{~cm}$ in diameter). Dishes of 20 seeds each were placed in the dark, at $5^{\circ} \mathrm{C}$, for a period of eight weeks for vernalization. Afterwards the seeds were kept at a constant temperature of $23^{\circ} \mathrm{C}$ with a $16 / 8 \mathrm{~h}$ day/night photoperiod. Each treatment consisted of five Petri dish replications.

\section{Evaluation of seed germination}

Germination was observed in one-week intervals for a period of 10 weeks. Seedlings with two fully developed cotyledons were scored as germinated. Preliminary calculations, after eight weeks from sowing the seeds, allowed us to determine the germination energy (the number of seeds available for rapid germination). This is expressed as a percentage. The time after which the germination energy was calculated was established according 
to the instructions published by the International Seed Testing Association (ISTA) (Anonymous 2003). A final calculation was carried out when all living seeds germinated. In this manner, the rate of germination can be expressed as a percentage. Seedling viability was estimated as the fresh weight of whole seedlings. Inbreeding depression coefficients for germination ability and average weight of a single seedling for each progeny were calculated as: $\delta=1-$ ws/wo, where ws and wo were the inbred trait value and outbred trait value, respectively (Agren and Schemske 1993). Duncan's multiple range t-test was used for mean separation at $\mathrm{p}=0.05$.

\section{RESULTS AND DISCUSSION}

Out of the 10 tested cultivars, three cultivars - Paula, Selva and Ostara - produced no viable $\mathrm{S}_{1}$ plants. Two others-Elkat and Elsanta-gave no $\mathrm{S}_{2}$ progeny. It has been shown that strawberry seeds germinate nonsimultaneously and their germination rates depend on the genotypic characteristics of the species. Seeds obtained by cross-pollination (outbreeding) demonstrated a very good germination rate. At the same time, relatively low germination rates and the partial death of seedlings have been reported in several studies (Marta et al. 2004, Baturin and Ambros 2010). The frequency of these symptoms is determined by the action of lethal genotypic factors typical for outbreeding or inbreeding. The multiplicity of systems and ways of seed formation in $F . \times$ ananassa provides a wide genetic variability in seed progeny, which is necessary for primary selection. A number of experiments have been carried out to develop inbred lines in strawberries and to test them in breeding programs (Spangelo et al. 1971, Hulewicz and Hortyński 1979, Niemirowicz-Szczytt 1989, Żurawicz 1990, Shaw 1995, 1997, Kaczmarska 2012). The authors of all the above papers reported that after the first and second self-pollination, plant viability decreased considerably, which made it practically impossible to develop progeny for most cultivars.

During the study a large genotypic difference between the examined objects was observed. Each of the tested cultivars reacted to the selfing in a different way. Figure 1 demonstrates that, in the case of the 'Chandler' and 'Teresa' hybrids, the best germination was displayed by seeds obtained after open pollination. Whereas in the case of 'Kent' and clone 1387, the seeds of the $\mathrm{S}_{4}$ generation germinated most successfully. The progeny 'Chandler' $\mathrm{S}_{1}$ showed a high reduction in seed germination at the beginning of the experiment followed by an increase of $21 \%$.

As reported by Melville et al. (1980), four inbred strawberry selections were selfed, intercrossed and outcrossed to two non-inbred selections. The latter were also intercrossed and selfed. Most progenies germinated as well as or better than the control outcross between two vigorous non-inbred clones. The germination of an $\mathrm{S}_{3}$ progeny was lower than the control. In general, inbreeding reduced seedling vigor while intercrossing or outcrossing restorer vigor.

The average weight of a single seedling for all $\mathrm{S}_{1}$ and $\mathrm{S}_{4}$ progenies was not significantly different from those obtained by open pollination. The highest weight of a single seedlings was observed in the case of progeny 'Chandler' $S_{1}$ and 'Kent' (7) $\mathrm{S}_{4}$ (data not shown). The lowest weight of seedlings was from the progeny 'Chandler' (123) $\mathrm{S}_{4}$ and clone $1387 \mathrm{~S}_{1}$. The inbreeding coefficient estimated for this trait amounted to 0.08 in the case of the $\mathrm{S}_{1}$ progeny, whereas it was 0.23 in the case of the $S_{4}$ progeny.

The highest energy of germination, or the number of seeds capable of rapid germination, was exhibited by the seeds of 'Teresa' hybrids from open pollination (75\%) and 'Kent' (7) $\mathrm{S}_{4}(74 \%)$ (Tab. 1). In the $S_{1}$ progeny, the energy of germination was low - on average $10.8 \%$, ranging from $1.0 \%$ (clone $1387 \mathrm{~S}_{1}$ ) to $20.0 \%$ ('Senga Sengana' $\mathrm{S}_{1}$ ).

As shown in Table 1, germination ability was the highest in the population of 'Teresa' derived from open pollination (82\%) and the 'Kent' (7) $\mathrm{S}_{4}$ population $(78 \%)$. Observations of four cultivars and one advanced breeding clone have shown evident differences in sensitivity to inbreeding during in vitro germination. These differences have a genetic background and might be exploited in breeding. Most of the variation observed was due to the general ability of the seeds to germinate.

An experiment conducted by Rho et al. (2008) attempted to solve the problem associated with inbred line breeding of strawberry. For this purpose, inbreeding depression and percent germination, categorized by the generation of individuals with non-inbreeding depression to be selected and individuals with inbreeding depression to be eliminated, was researched. When the percent germination of the inbreeding depression plant and non-inbreeding depression plant in lines originated from the Akihime cultivar were compared, there was no difference. However, in lines originated from the Johong and Sachinoka cultivars, the percent 

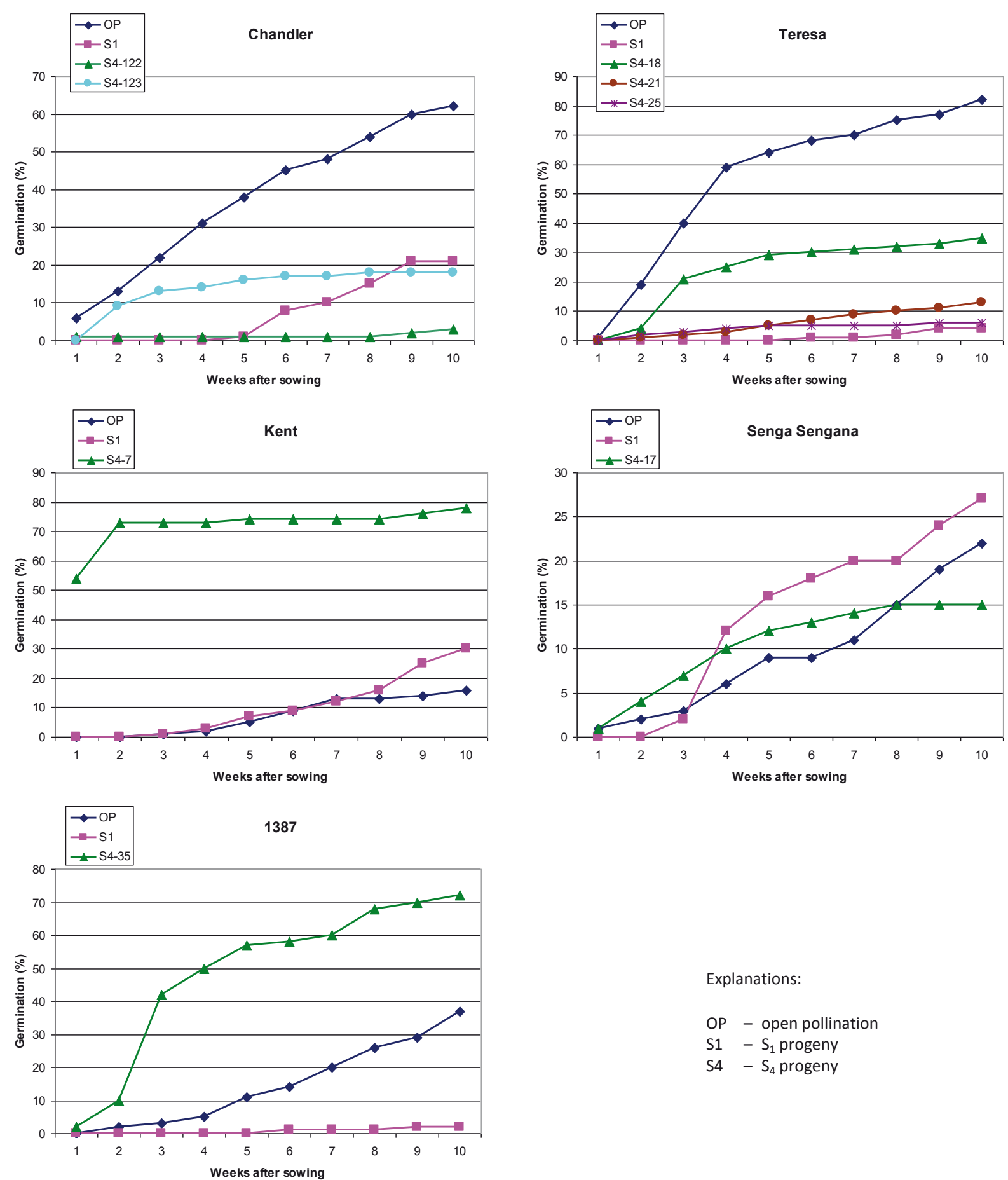

Figure 1. Seed germination of 4 cultivars and breeding clone 1387 of strawberries and their inbred offspring under in vitro culture conditions

germination of inbred plants was remarkably lower. Inbreeding depression occurred in the next generations of lines, although its degree varied.

In subsequent studies, Rho et al. (2012) reported that the germination percentages in the $\mathrm{S}_{1}-\mathrm{S}_{9}$ generations of inbred lines derived from three strawberry cultivars - Akihime, Johong and Sachinoka - showed an increase in the $\mathrm{S}_{5}$ generation and remained at $75-80 \%$ after the $S_{6}$ generation.
Continued self-pollination of octoploid strawberry over several generations resulted in a progressive decrease in yield, plant height and leaf area.

The highest inbreeding depression $(\delta=0.95)$ occurred in the offspring 'Teresa' $\mathrm{S}_{1}, 1387 \mathrm{~S}_{1}$ and 'Chandler' (122) $\mathrm{S}_{4}$. The average inbreeding depression coefficient for generation $S_{1}$ (0.62) was twice as high as in generation $\mathrm{S}_{4}(0.31)$. These findings are in agreement with a report 
Table 1. Seed germination and weight of seedlings of four cultivars and one breeding clone of strawberries and their inbred offspring $\left(\mathrm{S}_{1}\right.$ and $\left.\mathrm{S}_{4}\right)$

\begin{tabular}{|c|c|c|c|c|c|}
\hline Cultivar / progeny & $\begin{array}{l}\text { Average number } \\
\text { of seedlings per } \\
\text { plate }\end{array}$ & $\begin{array}{l}\text { Total weight of } \\
\text { seedlings } \\
\text { (g) }\end{array}$ & $\begin{array}{c}\text { Germination } \\
\text { energy } \\
(\%)\end{array}$ & $\begin{array}{l}\text { Germination } \\
\text { ability } \\
(\%)\end{array}$ & $\begin{array}{c}\text { Inbreeding } \\
\text { coefficient of } \\
\text { germination } \\
\text { ability } \\
(\delta)\end{array}$ \\
\hline Teresa OP* & $16.4 \mathrm{a}^{* *}$ & $1.118 \mathrm{ab}$ & $75.0 \mathrm{a}$ & $82.0 \mathrm{a}$ & - \\
\hline Senga Sengana OP & $4.4 \mathrm{~d}$ & $0.237 \mathrm{~b}$ & $15.0 \mathrm{~d}$ & $22.0 \mathrm{~d}$ & - \\
\hline Kent OP & $3.2 \mathrm{~d}$ & $0.296 \mathrm{ab}$ & $13.0 \mathrm{~d}$ & $16.0 \mathrm{~d}$ & - \\
\hline Chandler OP & $12.4 \mathrm{abc}$ & $0.814 \mathrm{ab}$ & $54.0 \mathrm{abc}$ & $62.0 \mathrm{abc}$ & - \\
\hline 1387 OP & $7.4 \mathrm{bcd}$ & $0.450 \mathrm{ab}$ & $26.0 \mathrm{dc}$ & $37.0 \mathrm{bcd}$ & - \\
\hline Mean OP & $8.8 \mathrm{~A}$ & $0.583 \mathrm{~A}$ & $36.6 \mathrm{~A}$ & $43.8 \mathrm{~A}$ & - \\
\hline Teresa $\mathrm{S}_{1}$ & $0.8 \mathrm{~d}$ & $0.038 \mathrm{~b}$ & $2.0 \mathrm{~d}$ & $4.0 \mathrm{~d}$ & 0.95 \\
\hline Senga Sengana $S_{1}$ & $5.4 \mathrm{~cd}$ & $0.275 \mathrm{~b}$ & $20.0 \mathrm{dc}$ & $27.0 \mathrm{~cd}$ & -0.23 \\
\hline Kent $\mathrm{S}_{1}$ & $6.0 \mathrm{~cd}$ & $0.354 \mathrm{ab}$ & $16.0 \mathrm{~d}$ & $30.0 \mathrm{~cd}$ & -0.87 \\
\hline Chandler $\mathrm{S}_{1}$ & $4.2 \mathrm{~d}$ & $0.199 \mathrm{~b}$ & $15.0 \mathrm{~d}$ & $21.0 \mathrm{~d}$ & 0.66 \\
\hline $1387 \mathrm{~S}_{1}$ & $0.4 \mathrm{~d}$ & $0.009 \mathrm{~b}$ & $1.0 \mathrm{~d}$ & $2.0 \mathrm{~d}$ & 0.95 \\
\hline Mean $\mathrm{S}_{1}$ & $3.4 \mathrm{C}$ & $0.175 \mathrm{C}$ & $10.8 \mathrm{C}$ & $16.8 \mathrm{C}$ & 0.62 \\
\hline Teresa (18) $\mathrm{S}_{4}$ & $7.0 \mathrm{bcd}$ & $0.340 \mathrm{ab}$ & $32.0 \mathrm{bcd}$ & $35.0 \mathrm{bcd}$ & 0.57 \\
\hline Teresa (21) $\mathrm{S}_{4}$ & $2.6 \mathrm{~d}$ & $0.102 \mathrm{~b}$ & $10.0 \mathrm{~d}$ & $13.0 \mathrm{~d}$ & 0.84 \\
\hline Teresa $(25) \mathrm{S}_{4}$ & $1.2 \mathrm{~d}$ & $0.059 \mathrm{~b}$ & $5.0 \mathrm{~d}$ & $6.0 \mathrm{~d}$ & 0.93 \\
\hline Senga Sengana (17) $\mathrm{S}_{4}$ & $3.0 \mathrm{~d}$ & $0.173 \mathrm{~b}$ & $15.0 \mathrm{~d}$ & $15.0 \mathrm{~d}$ & 0.32 \\
\hline $\operatorname{Kent}(7) \mathrm{S}_{4}$ & $15.6 \mathrm{a}$ & $1.453 \mathrm{a}$ & $74.0 \mathrm{a}$ & $78.0 \mathrm{a}$ & -3.87 \\
\hline Chandler (122) $\mathrm{S}_{4}$ & $0.6 \mathrm{~d}$ & $0.039 \mathrm{~b}$ & $1.0 \mathrm{~d}$ & $3.0 \mathrm{~d}$ & 0.95 \\
\hline Chandler (123) $\mathrm{S}_{4}$ & $3.6 \mathrm{~d}$ & $0.073 \mathrm{~b}$ & $18.0 \mathrm{~cd}$ & $18.0 \mathrm{~d}$ & 0.71 \\
\hline $1387(35) \mathrm{S}_{4}$ & $14.4 \mathrm{ab}$ & $0.772 \mathrm{ab}$ & $68.0 \mathrm{ab}$ & $72.0 \mathrm{ab}$ & -0.95 \\
\hline Mean $\mathrm{S}_{4}$ & $6.1 \mathrm{~B}$ & $0.376 \mathrm{~B}$ & $27.9 \mathrm{~B}$ & $30.0 \mathrm{~B}$ & 0.31 \\
\hline
\end{tabular}

*Open pollination (OP); **Values marked with the same letter do not differ significantly at $\alpha=0.05$

by Niemirowicz-Szczytt (1989) showing that the germination percentage slightly increases with the process of selfing generations. However, the germination percentage showed significant differences within lines derived from a cultivar, even when compared to lines derived from other cultivars.

Baturin and Ambros (2010) compared the seed germination dynamics of parthenogenetic progenies of the strawberry cultivar Purpurovaya during inbreeding, outbreeding and agamospermy. Seeds from the outbreeding germinated within 46 days, seeds from self-pollination within 68 days at a slightly higher proportion of germinated seeds (80.0\%) compared to the variant with outbreeding (76.4\%). It was shown that the revealed differences are caused by genotypic conditions. The seed germination of progenies is much higher during inbreeding and outbreeding than that of the original cultivar from which they were breeding.

The obtained results indicate that in the case of strawberries, inbreeding depression for the germination of seeds decreased in the successive inbreeding generations and was lower in the fourth generation compared to the $S_{1}$ generation, which is consistent with data presented by other authors. Kaczmarska (2012) reported that the average fruit yield per plant in inbred lines of strawberry appeared to be much lower than that of the standard cultivars (inbreeding depression for this trait decreased in successive inbred generations and amounted to 52.5 for $\mathrm{S}_{1}, 36.6$ for $\mathrm{S}_{2}$ and 22.0 for $\mathrm{S}_{3}$ ). Moreover, a significant correlation exists between inbreeding depression and selfing/outcrossing species, i.e. repeated selfing reduces the magnitude of depression. In contrast, outcrossing usually increases heterozygosity, which tends to produce genotypes better adapted to different environmental conditions. It has been depicted that different cultivars of strawberry differ in terms of the degree of inbreeding depression and percent germination. This problem in the inbred line breeding of strawberry can be solved by selecting vigorous and productive plants from the early selection. 


\section{CONCLUSIONS}

1. Achenes of strawberry obtained by inbreeding and by open pollination showed different germination rates owing to their genotypic differences.

2. The average weight of a single seedling derived from open pollination did not differ significantly from seedlings obtained by self-pollination.

3. Generally, the germination of seeds from self-pollination was significantly lower for $\mathrm{S}_{1}$ offspring, whose depression was 0.62 , in comparison with the $\mathrm{S}_{4}$ seedlings, whose depression was 0.31 .

\section{REFERENCES}

Agren J., Schemske D.W., 1993. Outcrossing rate and inbreeding depression in two annual monoecious herbs, Begonia hirsuta and B. semiovata. Evolution 47: 125-135.

Anonymous, 2003. International rules for seed testing. International Seed Testing Association (ISTA), Zürich, Switzerland.

Baturin S.O., Ambros E.V., 2010. Peculiarities of the seed germination of agamospermic seedlings Fragaria $\times$ ananassa Duch. in different breeding systems. Agric. Biology 5: 87-91.

Charlesworth D., Charlesworth B., 1987. Inbreeding depression and its evolutionary consequences. Ann. Rev. Ecol. Syst. 18: 237-268.

Chaves L.J., Vencovsky R., Silva R.S.M., Zucchi M.I., 2010. Estimating inbreeding depression in natural plant populations using quantitative and molecular data. Conserv. Genet. 1007: 125-132.

Duczmal K.W., 1993. Horticultural seed science. AR w Poznaniu.

Duczmal K.W., Tucholska H., 2000. Seed science. Tom 1. PWRiL, Poznań.

Hulewicz T., Hortyński J., 1979. Effect of inbreeding and its use in strawberry breeding. Genet. Pol. 20: 541-547.
KACZMARSKA E., 2012. Inbreeding depression for yield and yield components in Fragaria $\times$ ananassa Duch. Acta Sci. Pol., Hortorum Cultus 11: 57-68.

Marta A.E., Camadro E.L., Diaz-Ricci J.C., Castagnaro A.P., 2000. Breeding barriers between the cultivated strawberry, Fragaria $\times$ ananassa, and related wild germplasm. Euphytica 136: 139-150.

Melville A.H., Galleta G.J., Draper A.D., NG T.J., 1980. Seed germination and early seedling vigor in progenies of inbred strawberry selections. HortScience 15: 749-750.

Murashige T., Skoog F., 1962. A revised medium for rapid growth and bio-assays with tobacco tissue cultures. Physiol. Plant. 15: 473-497.

Niemirowicz-SzczytT K., 1989. Preliminary studies in inbreeding in strawberry Fragaria $\times$ ananassa Duch. Acta Hort. 265: 97-104.

Rho I.R., Cho Y.S., Cheong J.W., Jeong H.J., 2008. Effect of generation advancement by inbreeding on inbreeding depression and seed germination in strawberry. Korean J. Hortic. Sci. 26: 164-167.

Rho I.R., Woo J.G., Jeong H.J., Jeon H.Y., Lee C.H., 2012. Characteristics of $F_{1}$ hybrids and inbred lines in octoploid strawberry (Fragaria $\times$ ananassa Duchesne). Plant Breeding 131: 550-554.

SHAw D.V., 1995. Comparison of ancestral and current - generation inbreeding in an experimental strawberry breeding population. Theor. Appl. Genet. 90: 237-241.

SHAw D.V., 1997. Trait mean depression for secondgeneration inbred strawberry populations with and without parent selection. Theor. Appl.Genet. 95: 261264.

Spangelo L.P.S., Hsu C.S., Fejer S.O., Watkins R., 1971. Inbred line $x$ tester analysis and the potential of inbreeding in strawberry breeding. Can. J. Genet. Cytol. 13: 460-469.

ŻURAWICZ E., 1990. Heritability of the most important traits of strawberry (Fragaria $\times$ ananassa Duch.). ISK, Skierniewice.

Received July 29, 2014; accepted November 25, 2014 